\title{
Expression patterns of endothelial and inducible nitric oxide synthase isoforms in corpora lutea of pseudopregnant rabbits at different luteal stages
}

\author{
C Boiti, D Zampini, G Guelfi, F Paolocci ${ }^{1}$, M Zerani $^{2}$ and \\ A Gobbetti ${ }^{2}$ \\ Dipartimento di Scienze Biopatologiche Veterinarie, Università di Perugia, Via S Costanzo 4, I-06126 Perugia, Italy \\ ${ }^{1}$ Istituto Ricerche Miglioramento Piante Foraggere, CNR, Via Madonna Alta 130, Perugia, Italy \\ ${ }^{2}$ Dipartimento di Biologia Molecolare, Cellulare e Animale, Università di Camerino, Camerino, Italy \\ (Requests for offprints should be addressed to C Boiti; Email: cboiti@unipg.it)
}

\begin{abstract}
Total activity of nitric oxide (NO) synthase (NOS) and expression of both endothelial (eNOS) and inducible (iNOS) isoforms were examined in corpora lutea (CL) of rabbits across pseudopregnancy by quantitative RT-PCR analysis, Western blot and immunohistochemistry. CL were collected at early- (day 4), mid- (day 9) and late- (day 13) luteal phases of pseudopregnancy. The PCR product of rabbit luteal eNOS was cloned and its direct sequence exhibited $90 \%$ homology with those of other species. The steady-state mRNA levels encoding eNOS remained fairly constant throughout both early- and mid-luteal stages of pseudopregnancy but dropped almost to half $(P \leq 0 \cdot 05)$ by day 13 . By contrast, luteal eNOS proteins increased 2 -fold $(P \leq 0 \cdot 05)$ from the early- to late-luteal
\end{abstract}

phase. Independently of CL age, iNOS mRNA was very poorly expressed while protein levels gradually declined from the early- to late-luteal stage. Intense eNOS-like immunoreactivity was detected in large luteal cells, while iNOS staining was targeted to a few, isolated cells, probably macrophages. Basal NOS activity was greater in day 4 CL than in both day 9 and day 13 CL.

These data are the first to characterize in rabbit CL the temporal expression patterns of NOS isoforms across different luteal stages of pseudopregnancy and, collectively, suggest the existence of an expressional control for this constitutive isoform, which might have a physiological role in regulating CL function during development.

Journal of Endocrinology (2002) 173, 285-296

\section{Introduction}

Nitric oxide (NO) has emerged as a relevant effector and messenger molecule mediating multiple biological actions in many systems, including vasodilatation, neurotransmission and cytotoxicity, under both normal and pathophysiological conditions (Moncada et al. 1991, Snyder \& Bredt 1992, Schmidt \& Walter 1994). In a variety of mammalian cell types, $\mathrm{NO}$ is produced from $\mathrm{L}$-arginine by the action of one of three different NO synthase (NOS) isoforms (Förstermann et al. 1995), two being constitutive, the endothelial (eNOS) and the neuronal, and one inducible (iNOS).

Following the first demonstration that both eNOS and iNOS isoforms are expressed in the ovary (Van Voorhis et al. 1995, Chatterjee et al. 1996, Zackrisson et al. 1996), an increasing amount of experimental works supports the hypothesis that $\mathrm{NO}$ may also have a significant role in the physiology of this organ by controlling several key functions such as ovarian steroidogenesis and luteolysis (Van
Voorhis et al. 1994, Olson et al. 1996, Motta \& Gimeno 1997, Vega et al. 1998, Fridén et al. 2000). The NO/NOS system has also been directly implicated in the ovulatory process as inhibitors of $\mathrm{NO}$ reduce the ovulation rate in vivo and in vitro in both rats and rabbits (Shukovski \& Tsafriri 1995, Bonello et al. 1996, Hesla et al. 1997, Yamauchi et al. 1997, Faletti et al. 1999, Nakamura et al. 1999).

Recent work from our laboratory determined the presence of NOS activity in corpora lutea (CL) of pseudopregnant rabbits, where $\mathrm{NO}$ was shown to exert a regulatory role on progesterone release in response to both luteolytic and luteotropic factors in vitro (Gobbetti et al. 1999, Boiti et al. 2000). However, the impact of NO on CL function still remains to be better elucidated and several key points on the mechanisms regulating $\mathrm{NO}$ production are still unclear (Van Voorhis et al. 1995, Jablonka-Shariff \& Olson 1997, Srivastava et al. 1997). Moreover, the specific cell types expressing both eNOS and iNOS isoenzymes have not been detailed in the rabbit CL. 
With this in view, the main objective was to characterize the expression patterns of both eNOS and iNOS in $\mathrm{CL}$ of rabbits in vivo across pseudopregnancy at both cellular, gene transcript and protein level by means of immunohistochemistry, RT-PCR analysis and immunoblotting. For this work, CL were collected in early-, mid- and late-luteal phases at days 4, 9 and 13 of pseudopregnancy respectively. These stages were purposely selected because the corresponding CL have been extensively characterized in our laboratory by in vitro models (Gobbetti et al. 1999, Boiti et al. 2000, 2001) and because they show selective age-dependent responsiveness to many luteolytic and luteotropic factors (Miller \& Keyes 1978, Boiti et al. 1998, Niswender et al. 2000).

\section{Materials and Methods}

Animals, hormonal regimen and luteal tissue collection

Luteal tissue was obtained from unmated New Zealand White (HY/CR strain) rabbits (Charles River Italia, Lecco, Italy) of 5 months of age, weighing $3 \cdot 5-3 \cdot 8 \mathrm{~kg}$. The animals were maintained at the University of Perugia Central Animal Facility under controlled conditions of light (14 h light:10 h darkness) and temperature $\left(18^{\circ} \mathrm{C}\right)$, with freely fed water and commercial pellets. All rabbits received an i.m. injection of $20 \mathrm{IU}$ of pregnant mare serum gonadotropin (Folligon; Intervet, Milan, Italy) followed 3 days later by an i.m. injection of $0.8 \mu \mathrm{g}$ of gonadotropin-releasing hormone $(\mathrm{GnRH})$ (Receptal; Hoechst-Roussel Vet, Milan, Italy) to induce pseudopregnancy. This ovulation procedure was effective in generating an average of 14 or $15 \mathrm{CL}$ per rabbit. The day of GnRH injection was designated day 0. Rabbits were killed on days 4, 9 and 13 of pseudopregnancy (five animals/day) by cervical dislocation. On the day of killing a blood sample was collected from each rabbit by venous puncture of the marginal ear vein for plasma progesterone assay. CL were promptly excised from the ovaries of each rabbit, rinsed with RNAse-free PBS and non-luteal tissue carefully dissected away with fine forceps under stereoscopic magnification. The CL employed for molecular biology, immunoblot analysis, and enzymatic studies of NOS activity were immediately frozen in liquid nitrogen and stored at $-196{ }^{\circ} \mathrm{C}$ until processed. The CL used for immunohistochemistry, immediately upon collection, were fixed in $100 \%$ ethanol for $48 \mathrm{~h}$ at $4{ }^{\circ} \mathrm{C}$, cleared in xylene, then infiltrated with xylene/paraffin at $53{ }^{\circ} \mathrm{C}$ for $30 \mathrm{~min}$ and, finally, embedded in paraffin, following routine tissue preparation procedures.

\section{RNA extraction and $c D N A$ synthesis}

For each animal, an average of eight to ten CL were used for total RNA extraction. Luteal tissues were homogenized in $1 \mathrm{ml}$ of the solution provided with TRIzol (Life
Table 1 Oligonucleotide sequences used as primers to amplify eNOS and iNOS by PCR in rabbit corpora lutea

\section{Direction Primer sequence}

\begin{tabular}{|c|c|c|}
\hline \\
\hline \multirow{2}{*}{$\begin{array}{l}\text { NOS gene } \\
\text { Endothelial }\end{array}$} & Forward & CAGTGTCCAACATGCTGCTGGAAATTG \\
\hline & Reverse & TAAAGGTCTTCTTCCTGGTGATGCC \\
\hline \multirow[t]{2}{*}{ Inducible } & Forward & CAGGACCACACCCCCTCGGA \\
\hline & Reverse & AGCCACATCCСGAGCCATGC \\
\hline
\end{tabular}

Technologies Italia, Giuliano Milanese, Milan, Italy) using the procedure described by the manufacturer. RNA pellets were air dried and resuspended in distilled RNAsefree water and stored at $-80^{\circ} \mathrm{C}$. Concentration of total RNA was determined spectrophotometrically $\left(\mathrm{OD}_{260}\right)$, and RNA integrity of each sample was assessed by electrophoresis of an aliquot of $3 \mu \mathrm{g}$ RNA in agarose formaldehyde gel using ethidium bromide staining. Genomic DNA contamination was prevented by treatment with deoxyribunoclease I (DNAase I Amp. Grade; Life Technologies) according to the manufacturer's instructions.

cDNA was synthesized in $20 \mu \mathrm{l}$ of final reaction mixture, using samples of $5 \mu \mathrm{g}$ total RNA in the presence of Superscript II reverse transcriptase (Life Technologies) as suggested by the manufacturer. The reaction was carried out in the RT buffer supplied with the enzyme. The reverse transcription mixture consisted of $1 \mathrm{mM}$ dNTPs and $100 \mathrm{ng}$ random hexamer primers (Life Technologies), and was carried out for $50 \mathrm{~min}$ at $45^{\circ} \mathrm{C}$ followed by an inactivation step for $10 \mathrm{~min}$ at $94{ }^{\circ} \mathrm{C}$. Genomic DNA contamination was checked by carrying samples through the PCR procedure without adding reverse transcriptase. The reverse transcription products were stored at $-20{ }^{\circ} \mathrm{C}$.

\section{Multiplex RT-PCR amplification of eNOS}

An aliquot $(1 \cdot 0 \mu \mathrm{l})$ of the resulting single-stranded cDNA was used as a template for the subsequent PCR amplification reaction containing two primer sets, one for the eNOS gene and the other for 18S rRNA (QuantumRNA 18S Internal Standards; Ambion, Austin, TX, USA), used as a housekeeping gene. As the gene sequence for rabbit eNOS was not available, the primer sets (Table 1) were based on those published for human eNOS (Van Voorhis et al. 1994) and were custom obtained from Life Technologies.

The PCR reaction was carried out with $0.5 \mu \mathrm{l}$ Taq DNA polymerase $(5 \mathrm{U} / \mu \mathrm{l}$, Platinum; Life Technologies), $1 \cdot 0 \mu \mathrm{l}$ dNTPs $(10 \mathrm{mM}), 5 \cdot 0 \mu \mathrm{l}$ Taq buffer $10 \times, 1 \cdot 0 \mu \mathrm{l}$ $(10 \mu \mathrm{M})$ of both forward and reverse eNOS primers, $2 \cdot 0 \mu \mathrm{l}$ of mixed $18 \mathrm{~S}$ primers with competimers (2:8 respectively), and RNAse-free water to $50 \mu \mathrm{l}$ final volume. Amplification was performed on a thermal cycler 
(GeneAmp, PCR System; Perkin Elmer Biosystems, Foster City, CA, USA). After an initial denaturation step $\left(94{ }^{\circ} \mathrm{C}, 150 \mathrm{~s}\right)$, the amplification profile consisted of 35 denaturation $\left(94^{\circ} \mathrm{C}, 15 \mathrm{~s}\right)$, annealing $\left(62{ }^{\circ} \mathrm{C}, 30 \mathrm{~s}\right)$, and extension $\left(72{ }^{\circ} \mathrm{C}, 45 \mathrm{~s}\right)$ reaction cycles before a final extension step at $72{ }^{\circ} \mathrm{C}$ for $10 \mathrm{~min}$. To minimize errors, within each experiment, the complete set of samples was processed in parallel in a single PCR using aliquots of the same PCR master mix. Each set of determinations was performed in triplicate.

Preliminary experiments were carried out to establish the optimal ratio between $18 \mathrm{~S}$ primers and their competimers, blocked primers which are mixed to attenuate the amplification rate of highly abundant $18 \mathrm{~S}$ rRNA.

\section{Multiplex RT-PCR amplification of iNOS}

The PCR amplification reactions were run on the same RT products as above by using primer sets for iNOS, based on known partial cDNA sequences (GenBank Accession No. U85094), and 18S rRNA (Table 1). The volume of the cDNA template, however, was doubled $(2 \cdot 0 \mu \mathrm{l}$ aliquot) and the ratio between $18 \mathrm{~S}$ primers and their competimers was 1:9. The amplification profile was also modified for the number of cycles that were increased to 40 and for the annealing temperature, raised to $68^{\circ} \mathrm{C}$.

\section{Analysis of amplification products}

The amplified products $(20 \mu \mathrm{l}$ of $50 \mu \mathrm{l}$ total reaction volume) were analyzed by electrophoresis on $2 \%$ agarose gel using ethidium bromide staining. One product of each luteal stage was electrophoresed on a single gel together with a negative control that contained no RNA and a standard DNA ladder. The gels were photographed using a digital camera and the background-corrected band intensities (absolute optical densities subtracted by the background levels taken from corresponding lanes) for each PCR product were quantified using Quantity One software (Bio-Rad Laboratories, Hercules, CA, USA). To evaluate the temporal changes in relative levels of NOS mRNAs, the band intensities for the target sequence of interest obtained from each aliquot of PCR products were normalized against those of the housekeeping $18 \mathrm{~S}$ rRNA co-amplified product in that aliquot. Values were expressed as arbitrary units of relative abundance of the specific target genes.

\section{DNA sequencing of eNOS}

The RT-PCR products of eNOS fragment were cloned in pGEM T-Easy vector (Promega, Madison, WI, USA) according to the supplier's instructions. Double-strand DNA sequencing of this clone was carried out using a Big Dye Terminator Kit (Perkin Elmer Biosystems) and

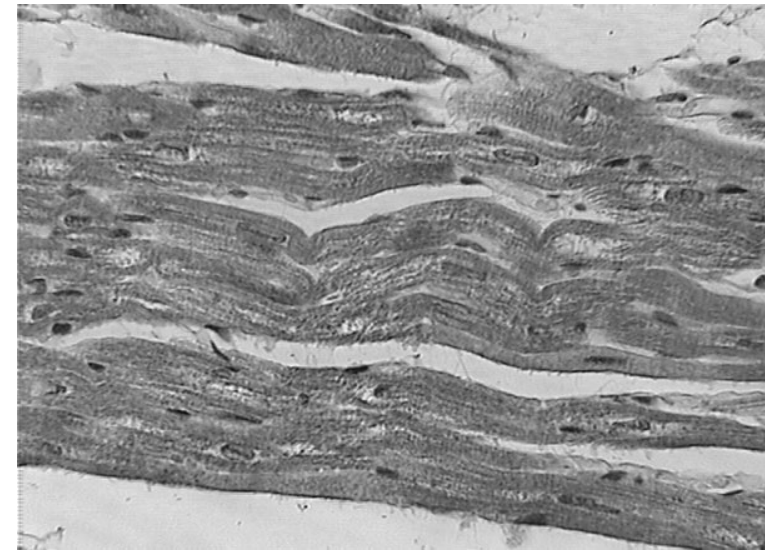

Figure $1 \mathrm{Immunolocalization}$ of eNOS in a section of rabbit myocardium which served as positive control for eNOS $(\times 400)$.

reaction products were run on ABIPRISM 310 Genetic Analyzer automated sequencer (Perkin Elmer Biosystems).

\section{NOS activity determination}

NOS activity was determined by monitoring the conversion of $\left[{ }^{3} \mathrm{H}\right] \mathrm{L}$-arginine (Sigma, St Louis, MO, USA) into $\left[{ }^{3} \mathrm{H}\right] \mathrm{L}$-citrulline with a commercial NOS assay kit (NOS detect ${ }^{\mathrm{TM}}$ Assay Kit; Alexis Corp. Läufelfingen, Switzerland), according to the experimental protocol previously described (Boiti et al. 2000). Following thawing at room temperature of luteal tissue, total NOS luteal activity of each rabbit was independently assayed in four CL randomly selected from the corresponding pool.

\section{Immunohistochemistry}

For each luteal stage, serial $3 \mu \mathrm{m}$ thick sections cut from paraffin-embedded CL were mounted on poly-L-lysinecoated glass slides and processed at the same time and under the same conditions. Briefly, the sections were dewaxed, re-hydrated in descending grades of alcohol and in water, and rinsed twice with PBS (0.01 M, pH 7.5). The sections were then incubated for $30 \mathrm{~min}$ with $0 \cdot 3 \%$ hydrogen peroxide in methanol to block endogenous peroxidase activity. All subsequent steps were carried out in moist chambers at room temperature. To prevent non-specific binding of primary antibody, the sections were pre-incubated for $30 \mathrm{~min}$ with $10 \%(\mathrm{v} / \mathrm{v})$ normal horse serum. The primary monoclonal antibodies, mouse anti-human eNOS and anti-mouse iNOS (Transduction Laboratories, Lexington, KY, USA), were both diluted 1:25 in PBS and added for $2 \mathrm{~h}$ to sections. After incubation with primary antibody, the sections were washed twice in PBS and then exposed for $2 \mathrm{~h}$ to purified biotinylated horse anti-mouse IgG (Vectastain Elite ABC Kit; Vector Laboratories, Burlingame, CA, USA) used as secondary 

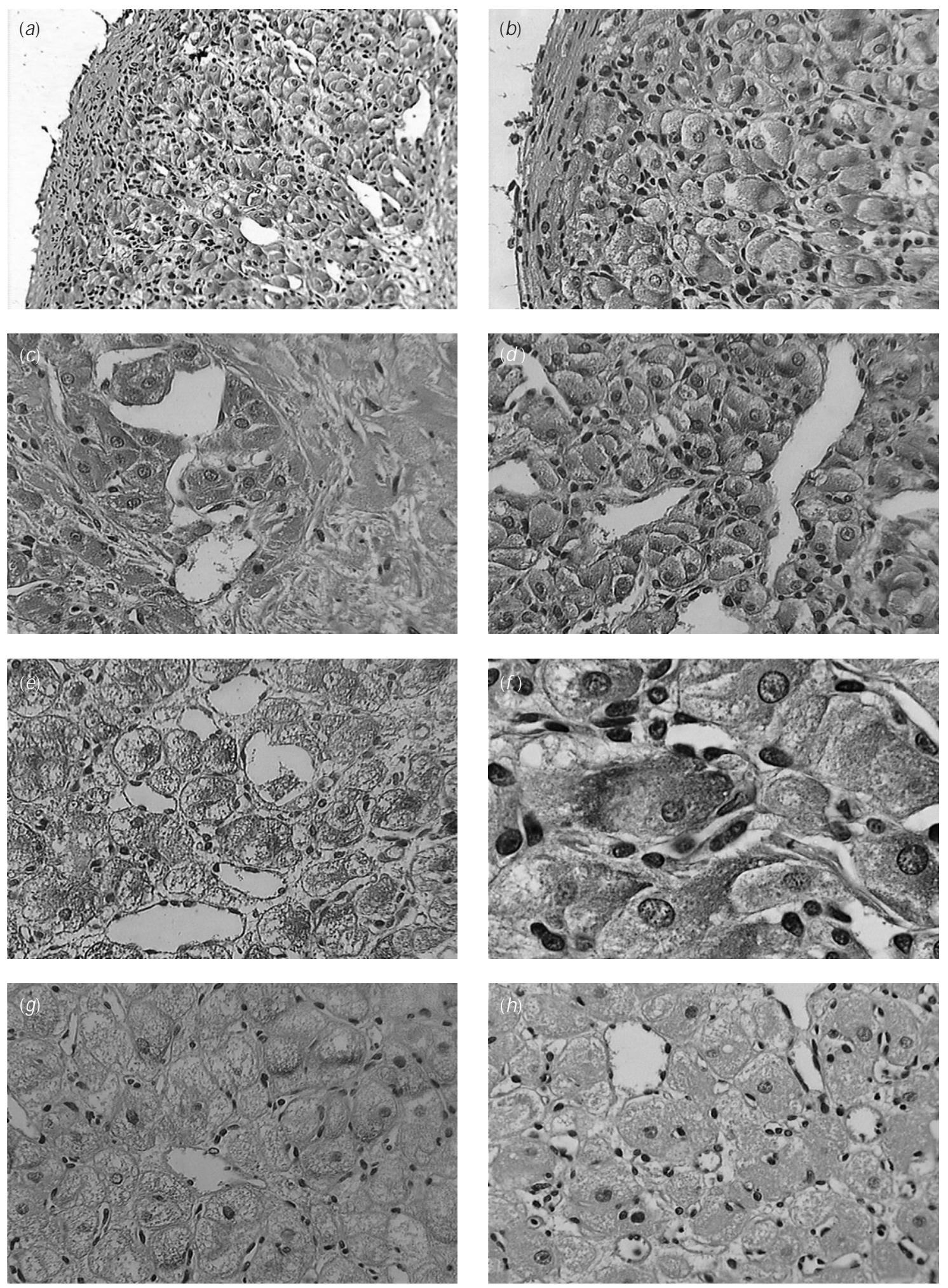
antibody. After PBS rinsing, the avidin-biotinylated complex peroxidase (ABC-P reagent; Vector Laboratories), prepared according to the manufacturer's instructions, was applied to the sections for $30 \mathrm{~min}$. The slides were then washed in PBS, and antigen-antibody binding sites were stained for $15 \mathrm{~min}$ in $0.05 \%$ 3,3'-diaminobenzidine chromogen solution (DAB substrate Kit for peroxidase; Vector Laboratories) and $0.02 \%$ hydrogen peroxide. After washing in tap water, the slides were dehydrated sequentially in ascending grades of alcohol and cleared in xylene. Finally, the sections were counter-stained with Harris's hematoxylin, washed in tap water and cover-slipped using aqueous mounting medium. The intensity of the staining was determined under a light microscope. Positive reactions were recognized as reddish brown precipitates. Sections in which the primary antibodies were omitted or substituted by non-immune mouse gamma globulin were used for the negative control of non-specific staining. These tissue sections were devoid of any significant staining. Sections of rabbit myocardium served as a positive control for eNOS (Fig. 1).

\section{Western blot analysis of eNOS and iNOS isoforms}

For the Western blotting analysis of eNOS and iNOS, total luteal proteins were extracted from CL of each rabbit in extraction buffer (Tris- $\mathrm{HCl} 10 \mathrm{mM} \mathrm{pH} \mathrm{7 \cdot 6,1 \%} \mathrm{SDS,}$ $1.0 \mathrm{mM}$ sodium ortho-vanadate). The homogenates were centrifuged at $14000 \mathrm{~g}$ for $15 \mathrm{~min}$ at $4{ }^{\circ} \mathrm{C}$. The protein concentrations in the resulting supernatant samples were determined using the Bio-Rad protein assay kit (Bio-Rad Laboratories). After heating at $95{ }^{\circ} \mathrm{C}$ for $5 \mathrm{~min}$, equivalent amounts of proteins $(10 \mu \mathrm{g})$ were separated using an electrophoresis system (Mini-Protean; Bio-Rad Laboratories) by discontinuous $10 \%$ SDS-PAGE with a $4 \%$ stacking gel for $60 \mathrm{~min}$ at $200 \mathrm{~V}$, constant current. The separated proteins were then electrophoretically transferred onto a nitrocellulose membrane (Protran; Schleicher \& Schuell, Dassel, Germany) for $1 \mathrm{~h}$ at $100 \mathrm{~V}$ constant current using a Mini Trans Blot (Bio-Rad) apparatus. The membranes were washed and blocked with $1 \%$ casein in Tris-buffered saline (TBS-C; Tris- $\mathrm{HCl}$, $20 \mathrm{mM}, \mathrm{pH} 7 \cdot 4, \mathrm{NaCl} 137 \mathrm{mM}$ ) and incubated overnight at $4{ }^{\circ} \mathrm{C}$ with anti-eNOS antibody diluted 1:2000 or anti-iNOS antibody diluted 1:5000, both from Transduction Laboratories. Membranes were then incubated with biotinylated anti-mouse IgG secondary antibody (Vector Laboratories) for $30 \mathrm{~min}$ at $37^{\circ} \mathrm{C}$ under gentle agitation. All antibody incubations and washings were performed in TBS-C. The avidin-biotinylated complex (ABC reagent; Vector Elite Kit) was then added. The DAB substrate for peroxidase (Vector Laboratories) was used for detection of immunoreactive bands. Mouse macrophage iNOS and human eNOS lysates (Transduction Laboratories) were used as negative and positive controls. The membranes were scanned using a flatbed scanner and the optical densities of the bands were quantified using Quantity One Software (Bio-Rad). Each specific band signal was corrected by subtracting the background levels taken within the same lane and reported as arbitrary units.

\section{Progesterone assay}

Progesterone concentrations in plasma samples were determined by RIA, using specific antibody according to the procedure reported elsewhere (Gobbetti et al. 1992). The compounds that cross-reacted with the antibody more than $0.2 \%$ were: progesterone $(100 \%)$, pregnenolone $(6 \cdot 2 \%)$ and $5 \beta$-pregnan-3 $\alpha-2$-one (1.7\%). Progesterone was extracted from plasma with ethyl ether. The assay sensitivity was $10 \mathrm{pg} / \mathrm{ml}$; intra-assay and inter-assay coefficients of variations were 6 and 11\% respectively.

\section{Statistical analysis}

All experiments were repeated at least three times. The ratios of each PCR product for the target gene normalized against $18 \mathrm{~S}$ co-amplified product were analyzed by twofactor ANOVA (luteal stage and gel as the two sources of variability) and a Newman-Keuls multi-comparison posttest. All statistical analyses were performed using Prism 3.0 (GraphPad Software, Inc., San Diego, CA, USA).

Results of mRNA and protein levels for both eNOS and iNOS, as well as total NOS activity, were expressed as means \pm S.E.M. of arbitrary units for the number of separate experiments as reported in Figure legends. Data relative to different stages of pseudopregnancy were analyzed by ANOVA (Sokal \& Rohlf 1981).

\section{Results}

\section{Immunolocalization of eNOS and $i N O S$ in $C L$}

Using a monoclonal antibody, positive eNOS staining was detected in all examined CL obtained from rabbits at different luteal phases of pseudopregnancy. Independently of CL age, eNOS-like immunoreactivity was localized primarily in the large luteal cells as indicated by the

Figure 2 Immunolocalization of eNOS in corpora lutea $(\mathrm{CL})$ of rabbits at different luteal stages. Representative photomicrographs of $3 \mu \mathrm{m}$ thick luteal sections immunostained with a primary monoclonal antibody (1:25) to human eNOS. CL were obtained from rabbits at days 4 , 9 and 13 of pseudopregnancy (a-d, e and g respectively). $(\mathrm{f})$ A higher magnification $(\times 1000)$ of a day 4 CL section. Positive staining is recognized as a brown precipitate. (h) A representative photomicrograph of a section prepared from day $4 \mathrm{CL}$ in which immunostaining was not observed when non-immune serum was substituted for the primary antibody $(\times 400)$. 

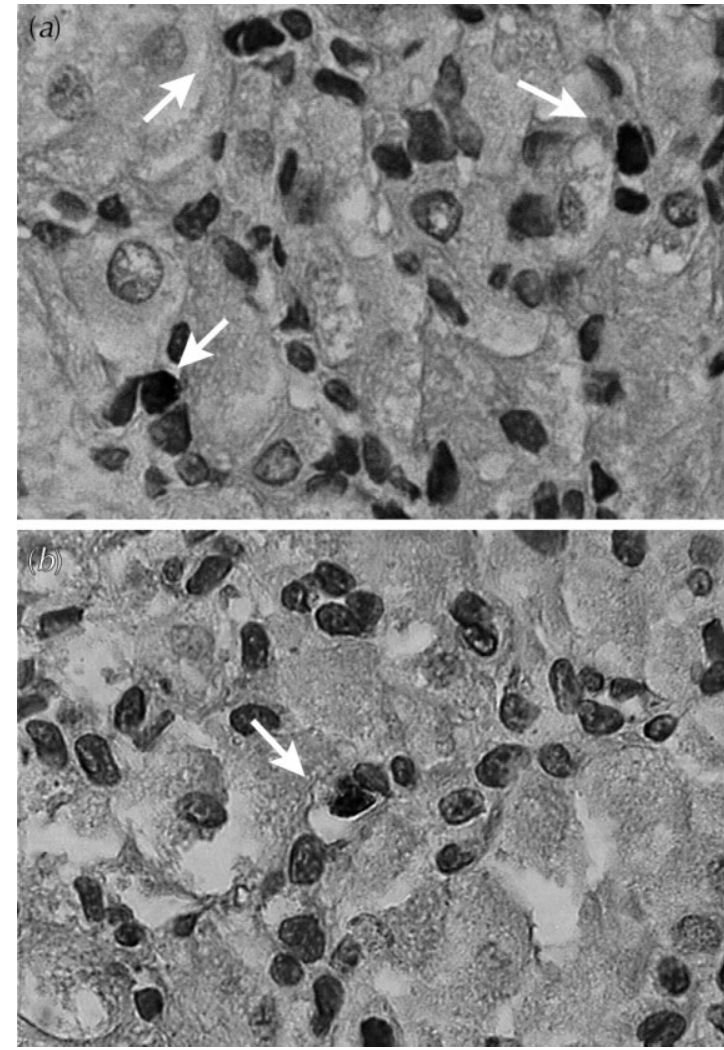

Figure 3 Immunolocalization of iNOS in rabbit $\mathrm{CL}$ obtained at day 4 of pseudopregnancy. ( $a$ and b) Representative photomicrographs of $3 \mu \mathrm{m}$ thick luteal sections $(\times 400)$ immunostained with a primary monoclonal antibody $(1: 25)$ to mouse iNOS. Arrows indicate positively stained cells.

abundant positive staining in their cytoplasm (Fig. 2a-g). Within most of these luteal cells, greater intensity of positive staining for eNOS was localized in the periphery of the cytoplasm, sometimes in a polar fashion (Fig. 2f). However, no obvious difference in the intensity of the staining was detectable between 4-, 9- and 13-day CL preparations. The diameter of individual luteal cells increased from day 4 to both days 9 and day 13. Staining was completely abolished when the primary antibody was substituted with non-immune serum (Fig. 2h), while staining was restricted in positive controls (data not shown). By means of a monoclonal antibody, a strong positive staining reaction for iNOS was also detectable within the CL, but limited to a few, isolated cells, usually localized near to capillaries, characterized by scant cytoplasm and non-steroidogenic appearance (Fig. 3). Occasionally, the iNOS-stained cells were found inside small blood vessels (Fig. 3b). With the aging of CL, the number of positive cells for iNOS appeared to decrease. Negative control sections incubated without the antiiNOS antibody were lacking in any staining (data not shown).
Validation of RT-PCR for luteal analysis of NOS isoforms

The relative RT-PCR assay employed here amplified eNOS (or iNOS) and 18S transcripts from whole luteal tissue in a single tube. The extremely abundant $18 \mathrm{~S}$ rRNA, whose expression remained fairly constant independently of the luteal phases, served as an internal control to which to normalize the samples. To assess the range of cycles over which both target and $18 \mathrm{~S}$ products were in a linear exponential phase of amplification, PCR for eNOS was performed between 30 and 45 cycles on cDNA generated from a single $\mathrm{RT}$ reaction, while that for iNOS between 35 and 45 cycles. eNOS and $18 \mathrm{~S}$ products accumulated at a constant rate between 30 and 40 cycles and between cycles 35 and 45 in the case of iNOS.

\section{Rabbit eNOS sequence}

The sequence of rabbit eNOS cDNA $486 \mathrm{bp}-$ long fragment has been registered in GenBank (Accession No. AF287158). It shows a $92 \%$ identity to the corresponding human eNOS segment.

\section{Gene expression of eNOS and iNOS $m R N A$ s during pseudopregnancy}

To study the steady-state levels of mRNA encoding both eNOS and iNOS during pseudopregnancy, samples of total RNA extracted from CL of individual rabbits at different luteal stages were analyzed by quantitative multiple RT-PCR, using primers specific for eNOS (Fig. 4) and iNOS (Fig. 5). The 485 and 537 bp amplification products obtained using primers designed from eNOS and iNOS matched the expected sizes based on the sequence of human eNOS and rabbit iNOS respectively. There were no amplified products from the negative RT controls. In each PCR reaction, 18S rRNA was also coamplified and used as internal standard for calculation of the relative abundance of target gene RNA. The gene expression of eNOS enzyme remained fairly constant in both early- and mid-luteal phases, but decreased $(P \leq 0 \cdot 05)$ to half in older CL at day 13 of pseudopregnancy (Fig. 4, right panel). Compared with eNOS transcript, luteal iNOS mRNA was poorly expressed and its levels gradually declined across pseudopregnancy from early- to lateluteal stages (Fig. 5, right panel).

\section{Luteal eNOS and iNOS protein expression by immunoblotting}

Protein immunoblot analysis was used to examine expression of eNOS and iNOS in whole extracts from CL of pseudopregnant rabbits. eNOS proteins of the predicted $130-135 \mathrm{kDa}$ size were detected in CL of all rabbits examined, while no signal was found in lysates of macrophages (Fig. 6, left) or when primary antibody was omitted 

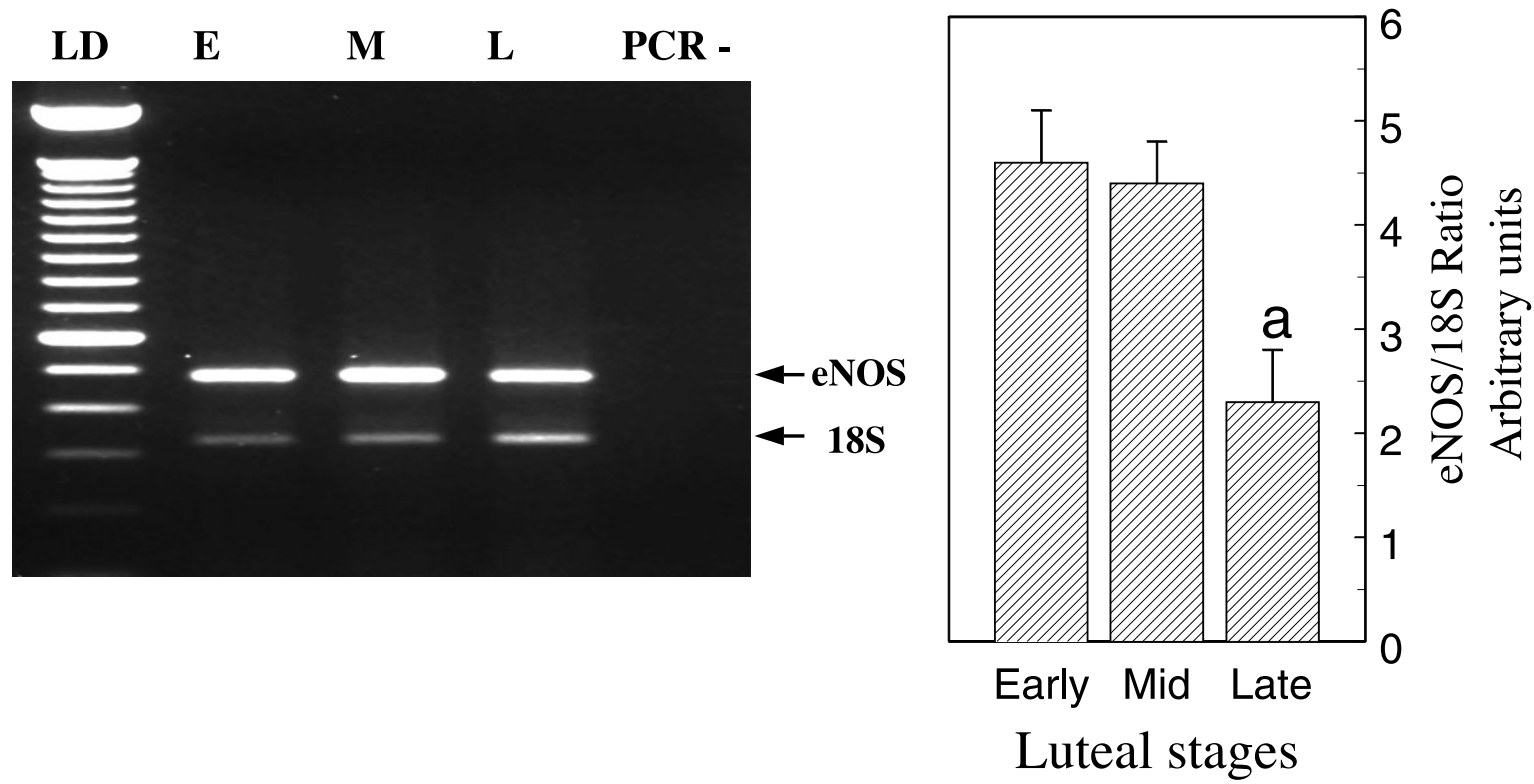

Figure 4 Gene expression of eNOS in CL of rabbits across pseudopregnancy at early- (day 4), mid- (day 9) and late- (day 13) luteal stages as determined by multiplex RT-PCR. For each day of pseudopregnancy, multiplex semi-quantitative PCR amplification of reverse transcribed RNA extracted from pooled $\mathrm{CL}$ of individual rabbits was performed as described in Materials and Methods for eNOS and housekeeping (18S) gene. The co-amplified products of each sample were analyzed in a $2 \%$ agarose gel by electrophoresis. Left panel: representative photograph of typical ethidium bromide-stained gel showing the presence of the expected $485 \mathrm{bp}$ amplification product yielded after RT-PCR using primers for both target eNOS and 18S (upper and lower band respectively) in lanes identified as E, M and L for the corresponding luteal stages. Lane LD is the kilobase DNA marker; lane PCR - represents a negative control of non-reversed-transcribed RNA submitted to PCR amplification. Right panel: quantitative data of the steady-state abundance for eNOS mRNA represent means \pm S.E.M. of combined results from five different rabbits for each luteal stage. The band intensity for the gene of interest in each PCR amplification product was normalized against that of $18 \mathrm{~S}$ in the same aliquot and reported in arbitrary units. A letter above a bar indicates a significantly different value $(P \leq 0 \cdot 05)$.

(data not shown). Luteal expression of eNOS protein progressively increased $(P \leq 0 \cdot 05)$ from early- to mid- and late-luteal phases. The amount of eNOS was $50 \%$ greater in day 9 CL than in day 4 CL. Its levels further increased 2-fold in day $13 \mathrm{CL}$ compared with CL of the early-luteal phase (Fig. 6, right panel). The immunoblot for the eNOS showed also two other bands of lower molecular mass of approximately $70-75 \mathrm{kDa}$, which might represent fragments of this enzyme. iNOS proteins of the expected $130 \mathrm{kDa}$ size were also found in all CL examined (Fig. 7, left) while no signal was obtained in endothelial cell lysates or when primary antibody was omitted. The expression of luteal iNOS proteins did not change during pseudopregnancy (Fig. 7, right panel). Western blot analysis probing iNOS in luteal tissue detected bands of molecular mass above and below that of the expected size. These proteins, of approximately 200, 80 and $72 \mathrm{kDa}$, are supposed to represent respectively a homodimeric form and fragments of the enzyme (Jablonka-Shariff \& Olson 1997, Coers et al. 1998, Watanabe et al. 1998).

\section{Total luteal NOS activity and plasma progesterone}

The total activity of NOS enzyme in rabbit CL was higher $(P \leq 0 \cdot 01)$ on day 4 of pseudopregnancy than on either day
9 or 13 (Fig. 8), thus confirming our previous results obtained from CL of the same age, but after $2 \mathrm{~h}$ in vitro culture (Gobbetti et al. 1999). Plasma progesterone concentrations (means \pm S.E.M.), used as a marker of luteal functionality, were high at days 4,9 and 13 of pseudopregnancy $(4 \cdot 2 \pm 0 \cdot 3,11 \cdot 6 \pm 0.5$ and $10 \cdot 3 \pm 0.6 \mathrm{ng} / \mathrm{ml}$ respectively) and consistent with the patterns of plasma progesterone levels observed in rabbits at the same luteal stage (Browning et al. 1980).

\section{Discussion}

The principal aim of this study was to identify eNOS and iNOS isoforms in rabbit CL and verify whether their expressions are regulated with a temporally specific pattern across different luteal stages of pseudopregnancy. Moreover, this work, which stems from our earlier studies in vitro, is the first to investigate coherently the activity and the functional expression of luteal NOS isoenzymes at both cellular and molecular levels in the rabbit.

Using immunohistochemistry, we confirmed for the first time the presence of positive eNOS- and iNOS-like materials in luteal tissue of pseudopregnant rabbits and the specific cell types expressing these two isoforms. 


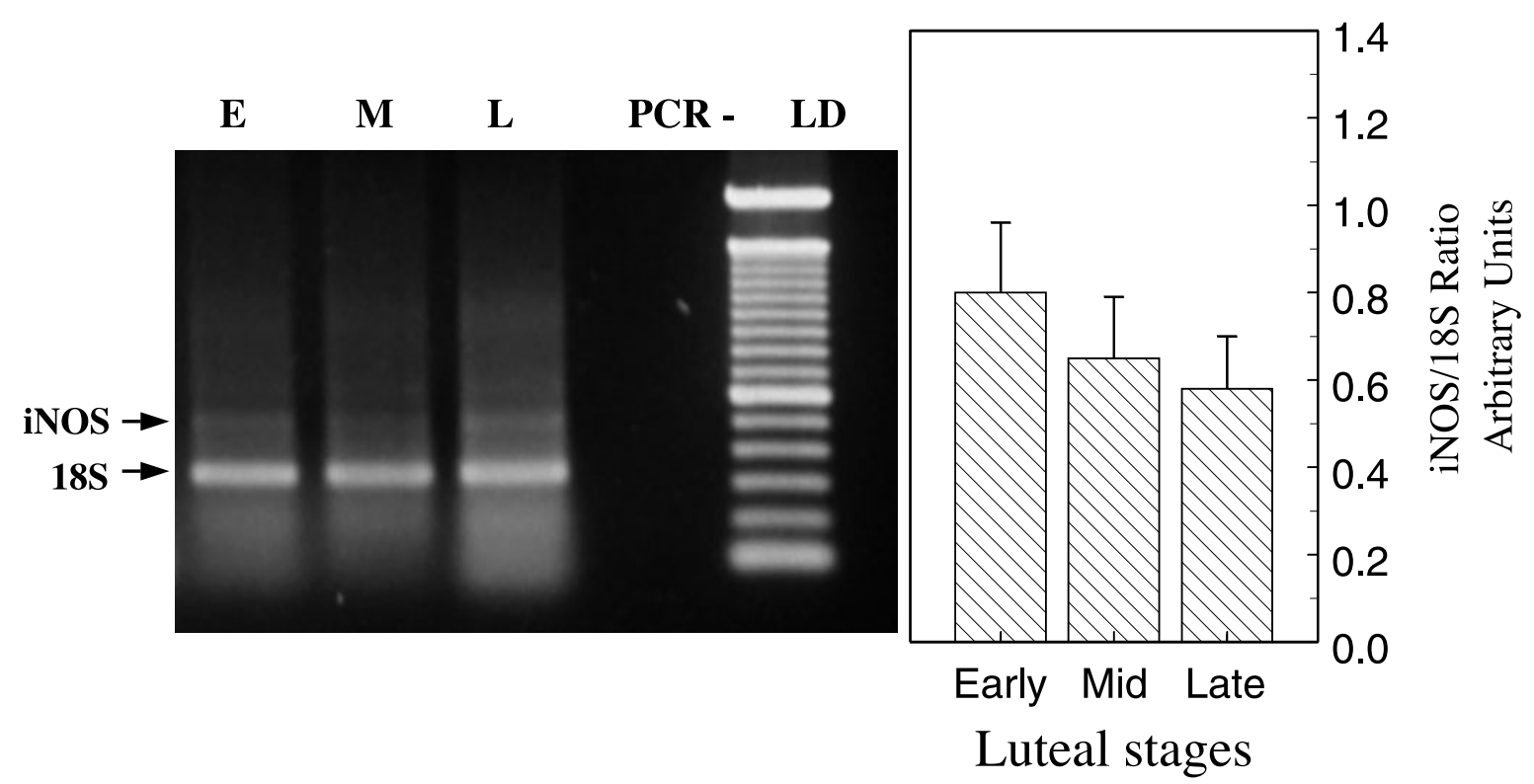

\begin{abstract}
Figure 5 Gene expression of iNOS in CL of rabbits across pseudopregnancy at early- (day 4), mid- (day 9) and late- (day 13) luteal stages as determined by multiplex RT-PCR. For each day of pseudopregnancy, multiplex semi-quantitative PCR amplification of reverse transcribed RNA extracted from pooled CL of individual rabbits was performed as described in Materials and Methods for iNOS and housekeeping (18S) gene. The co-amplified products of each sample were analyzed in a $2 \%$ agarose gel by electrophoresis. Left panel: representative photograph of typical ethidium bromide-stained gel showing the presence of the expected $537 \mathrm{bp}$ amplification product yielded after RT-PCR using primers for both target iNOS and 18S (upper and lower band respectively) in lanes identified as E, M and L for the corresponding days. Lane LD is the kilobase DNA marker; lane PCR - represents a negative control of non-reversed-transcribed RNA submitted to PCR amplification. Right panel: quantitative data of the steady-state abundance for iNOS mRNA represent means \pm S.E.M. of combined results from five different rabbits for each luteal stage. The band intensity for the gene of interest in each PCR amplification product was normalized against that of $18 \mathrm{~S}$ in the same aliquot and reported in arbitrary units.
\end{abstract}

Immunoreactive eNOS was mostly detectable in the cytoplasm of large luteal cells having steroidogenic capacity. On the other hand, we were unable to identify any clear specific staining for this isoform within the endothelium of luteal blood vessels, as found in rat ovary (Van Voorhis et al. 1995). In our study, a few positively iNOS-stained cells, which are probably macrophages, were also found in all luteal tissue preparations.

So far, localization of eNOS and iNOS in luteal tissue has been examined by immunohistochemistry only in CL of human and rat. Therefore, comparative clues to similar studies may be difficult to find, partly because of marked differences among species in CL structure and partly due to methodological reasons arising from differences in binding affinity and specificity of heterologous antibodies used by each investigator. Nevertheless, the spatial distribution of cells showing specific staining for eNOS we found in this study is similar to that described in CL of both rat (Chatterjee et al. 1996, Olson et al. 1996, Zackrisson et al. 1996, Jablonka-Shariff \& Olson 1997) and human (Vega et al. 1998, Fridén et al. 2000). Similar to our findings, a positive signal for iNOS was also observed within a few non-steroidogenic cells, probably macrophages, of human (Vega et al. 1998, Fridén et al. 2000) and rat CL (Olson et al. 1996, Jablonka-Shariff \& Olson 1997).

We further examined the expression patterns of both eNOS and iNOS isoforms in CL of rabbits using an RT-PCR technique and immunoblot analysis to assess the steady-state abundance of their gene transcripts and proteins throughout different stages of pseudopregnancy. To the best of our knowledge, this is the first study to evaluate their expression in CL tissue of rabbits. Amplification of the respective RNA resulted in a single PCR product of the expected size. Moreover, the cDNA fragment of the rabbit eNOS was analyzed by cloning and sequencing. Characterization of eNOS cDNA obtained from rabbit luteal tissue revealed that the $486 \mathrm{bp}$ sequence is $92 \%$ identical compared with human eNOS at the nucleotide level. In general, an 85-90\% identity, and greater than $90 \%$ similarity in eNOS, have been reported in the various species studied to date, indicating a remarkable conservation of this enzyme.

Luteal development across pseudopregnancy affected the level of eNOS mRNA, which remained fairly constant in both early- and mid-phase CL but was 


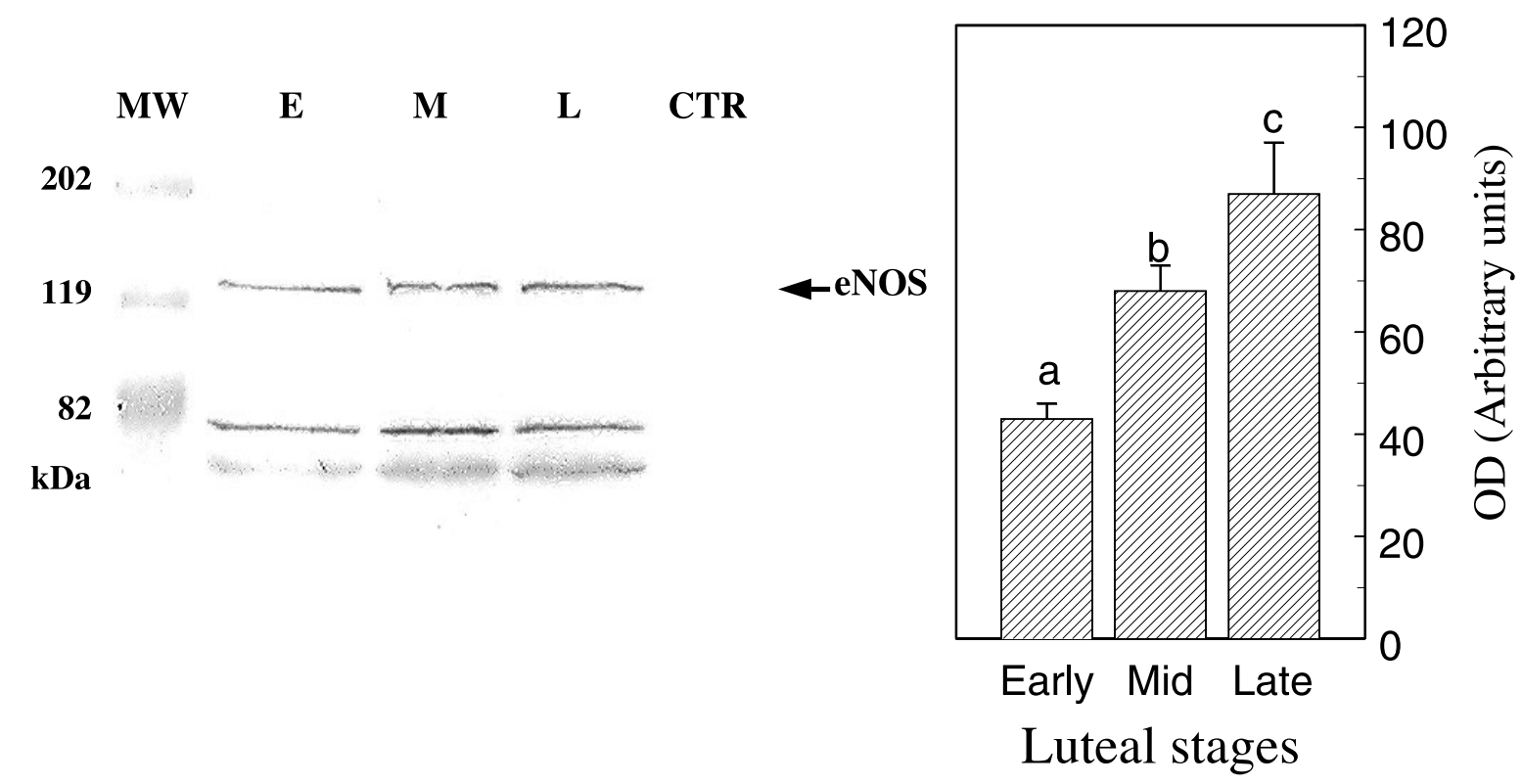

\begin{abstract}
Figure 6 Representative Western blots of eNOS protein (left panel) in rabbit CL during pseudopregnancy at early- (day 4), mid- (day 9) and late- (day 13) luteal stages. CL homogenates (10 $\mu \mathrm{g}$ ) were subjected to $10 \%$ SDS-PAGE followed by immunoblotting with a monoclonal antibody against human eNOS. Lanes $\mathrm{E}, \mathrm{M}$ and L identify the corresponding luteal stages. Lanes MW and CTR identify molecular mass standards and the negative control respectively. Right panel: quantitative analysis of luteal eNOS expression during different luteal stages. After scanning, the background-corrected optical densities of the immunoblot signals were quantified and expressed as arbitrary units. Columns represent means \pm S.E.M. of five rabbits for each luteal stage; different letters above bars indicate a significantly different value $(P \leq 0.05)$.
\end{abstract}

down-regulated in older CL. In humans, a 50-64\% reduction in eNOS mRNA abundance was observed in late- relative to both early- and mid-CL (Vega et al. 1998). Interestingly, however, in our experiments we found that eNOS proteins markedly increased during CL development from early- to late-luteal stages. Although it is often difficult to extrapolate mRNA data to actual protein content, the down-regulation of eNOS mRNA seen in older CL might be attributed to either a decreased rate of gene transcription and/or increased destabilization of the eNOS mRNA. Part of the explanation, however, may reside in the continuous remodeling process between the different sub-populations of cells that characterizes CL development in the rabbit and leads to changes in the relative ratio between luteal and non-luteal cells (Hoyer et al. 1986, Dharmarajan et al. 1988). The change in expression may also reflect differential, age-related, susceptibility of eNOS gene toward either specific inducers or inhibitors. Although the eNOS, being constitutive, does not depend upon new protein synthesis to rapidly synthesize and release $\mathrm{NO}$, increasing experimental evidence suggests that its expression in several cell types can be dynamically regulated by various factors and hormones (Weiner et al. 1994, Arnet et al. 1996, JablonkaShariff \& Olson 1997, Förstermann et al. 1998).

By contrast, the enhanced expression of eNOS protein suggests that de novo synthesis of additional eNOS by the
CL occurs during luteal development. Also, higher eNOS protein levels were expressed in human CL of late luteal phase compared with earlier and regressing stages (Fridén et al. 2000) and in rat ovaries 10 days after induced ovulation (Jablonka-Shariff \& Olson 1997). Whether the up-regulation of eNOS protein we observed in rabbit CL depends upon an increased translational rate or, rather, an increased half-life of the protein itself remains to be elucidated.

The present results confirm that CL of rabbit throughout different luteal stages of pseudopregnancy do indeed express iNOS mRNA and protein as well as CL of the other species examined so far (Van Voorhis et al. 1995, Zackrisson et al. 1996, Jablonka-Shariff \& Olson 1997, Srivastava et al. 1997, Fridén et al. 2000). In our study we found that iNOS mRNA transcripts are expressed without being exogenously induced in response to immunological or inflammatory factors. Their levels, however, are much less abundant than that of eNOS and, in fact, high cycle number was required to detect any signal, implying a low copy number of luteal iNOS mRNA. Moreover, iNOS mRNA constantly declined across pseudopregnancy from the early- to late-luteal stage. In the rat, iNOS mRNA expression was highest in the unstimulated immature rat ovary and dropped to very low levels in ovaries containing both early and mature CL 1 and 3 days after human chorionic gonadotropin (hCG)-induced ovulation 


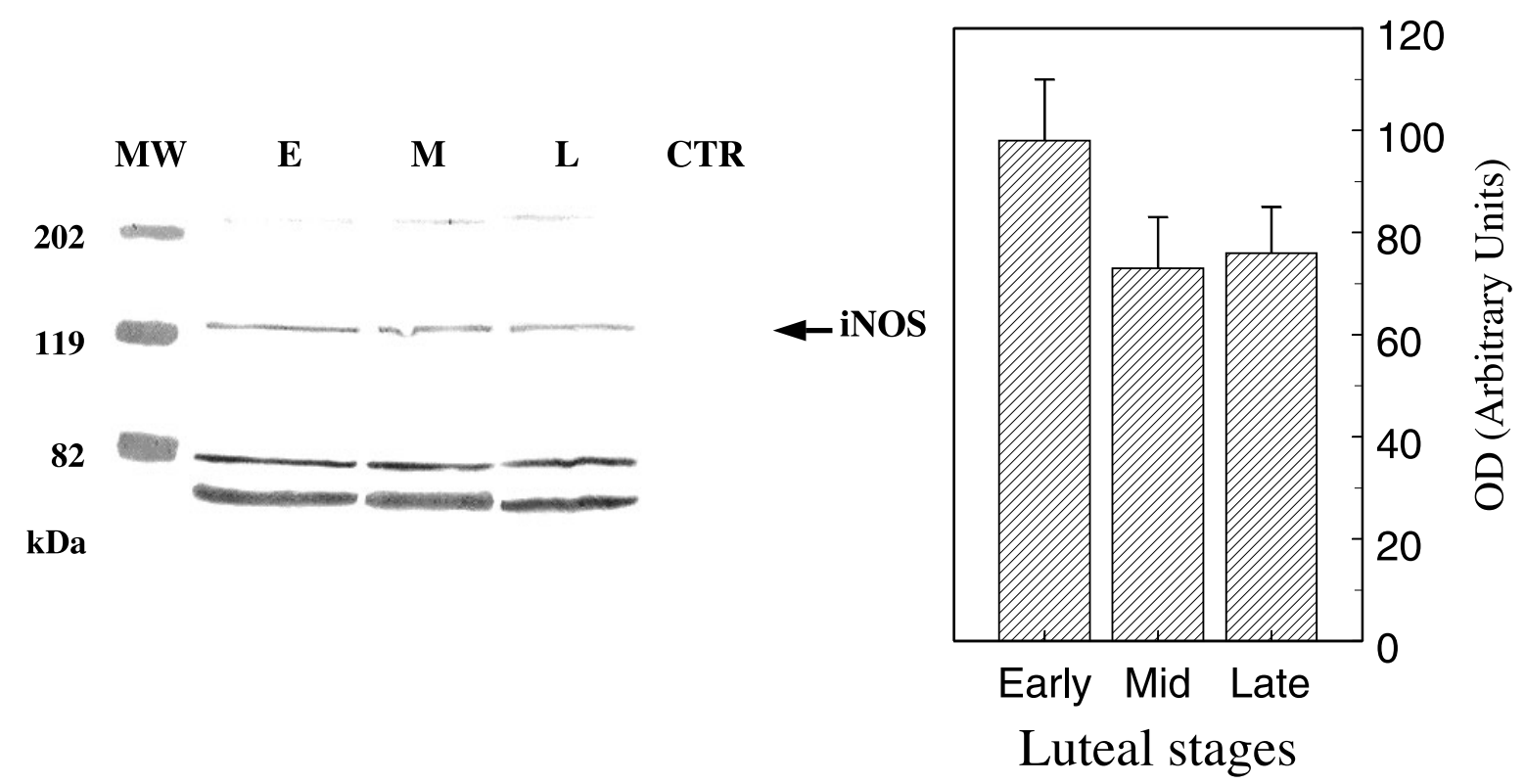

Figure 7 Representative Western blots of iNOS protein (left panel) in rabbit CL during pseudopregnancy at early- (day 4), mid- (day 9) and late- (day 13) luteal stages. CL homogenates $(10 \mu \mathrm{g})$ were subjected to $10 \%$ SDS-PAGE followed by immunoblotting with a monoclonal antibody against mouse iNOS. Lanes E, M and L identify the corresponding luteal stages. Lanes MW and CTR identify molecular mass standards and the negative control respectively. Right panel: quantitative analysis of luteal iNOS expression, during different luteal stages. After scanning, the background-corrected optical densities of the immunoblot signals were quantified and expressed as arbitrary units. Columns represent means \pm S.E.M. of five rabbits for each luteal stage.

(Jablonka-Shariff \& Olson 1997). However, information on iNOS expression is somewhat conflicting and differences among species are likely to be present. Thus, in our case, the amount of protein for iNOS decreases with aging of CL. In the rat, conversely, the pattern of ovarian iNOS protein is opposite as it markedly increases after hCGinduced ovulation, and the highest values are expressed by the 10-day-old ovaries having degenerating CL (JablonkaShariff \& Olson 1997). In human CL, iNOS protein levels did not show any clear phase-dependent variations at different luteal ages (Fridén et al. 2000). Typically, iNOS requires new protein synthesis to catalyze the formation of NO. The iNOS is up-regulated by several cytokines, such as interleukin- 1 , interferon- $\gamma$ and tumor necrosis factor- $\alpha$, although a large number of other cytokines and growth factors are known to transcriptically prevent its expression (Förstermann et al. 1995).

Here, we found that NOS total activity diminishes with the CL development from early- to mid-luteal stage, when the steroidogenesis is maximal (Holt 1989). These data are in accord with our previous in vitro results (Gobbetti et al. 1999, Boiti et al. 2000) and support the findings obtained in rat (Motta \& Gimeno 1997) and human CL (Vega et al. 1998). However, the finding that over the same time interval the eNOS protein expression almost undergoes a 2 -fold increase suggests that other factors, besides those affecting the transcription or stability of eNOS mRNA, may be involved in the down-regulation of NOS enzyme through modulation of its post-translational activity. In fact, in previous studies in vitro we have demonstrated that opposing intracellular signaling pathways carried out via phospholipase $\mathrm{C}$ and adenylate cyclase (Boiti et al. 2000) differently regulated NOS activity and, in turn, progesterone release. Interestingly, however, NOS activity increased again in older CL during the late-luteal phase, at day 13 of pseudopregnancy, when natural luteolysis usually begins concomitantly with the initial decline of peripheral plasma progesterone concentrations (Browning et al. 1980, Holt 1989). In the present study we have not attempted to differentiate the specific contribution to total activity between the two isoforms and therefore we cannot exclude that the increased NOS activity observed at both early- and late-luteal phases derives from iNOS.

In conclusion, our results indicate that both eNOS and iNOS, although at different levels, are not only expressed in CL of pseudopregnant rabbits but also regulated during luteal development. Taken together, both immunological and PCR methods have provided useful information on their expression and precise cell-type localization, from which ideas on their regulation can be better postulated. NOS activity, in fact, may be regulated at transcriptional, translational and post-translational levels.

RT-PCR demonstrated high levels of transcriptional expression for eNOS in total RNA extracted from CL of 


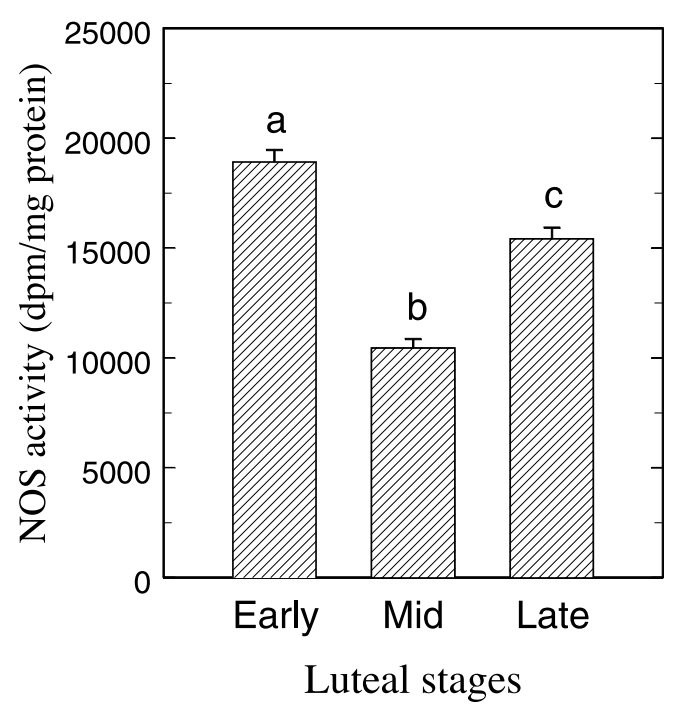

Figure 8 Basal NOS activity in rabbit CL during pseudopregnancy at early- (day 4), mid- (day 9) and late- (day 13) luteal stages. NOS activity was determined by conversion of ${ }^{3}[\mathrm{H}] \mathrm{L}$-arginine to ${ }^{3}[\mathrm{H}] \mathrm{L}$-citrulline. Results represent means \pm S.E.M. of five combined values for each day of pseudopregnancy and are expressed as d.p.m./mg wet tissue. Different letters above bars indicate a significantly different value $(P \leq 0 \cdot 05)$.

rabbits at different luteal stages of pseudopregnancy, whereas iNOS was barely present. Immunohistochemistry has provided the most accurate information on the cellular distribution and location of NOS isoforms in luteal tissue. Anatomically, the eNOS enzyme is located chiefly in the large luteal cells so that it is ideally suited to regulate luteal steroidogenesis and local blood flow. The iNOS enzyme is localized exclusively in a few non-steroidogenic cells, probably macrophages. Nevertheless, the occasional presence of resident macrophages expressing iNOS within the rabbit luteal tissue suggests that a paracrine modulation of the adjacent cells is possible through the release of a variety of secretory products and NO too. However, what stimuli actually regulate eNOS in large luteal cell populations or activate iNOS in immunological cells, together with their precise role, if any, remain to be unveiled.

\section{Acknowledgements}

The authors gratefully acknowledge the revision of the English text by Dr James Burge of the Linguistic Institute of Camerino University. This work was supported by a grant from Ministero per l'Istruzione, l'Università e la Ricerca.

\section{References}

Arnet UA, McMillan A, Dinerman JL, Ballermann B \& Lowenstein CJ 1996 Regulation of endothelial nitric-oxide synthase during hypoxia. Journal of Biological Chemistry 271 15069-15073.
Boiti C, Canali C, Zerani M \& Gobbetti A 1998 Changes in refractoriness of rabbit corpora lutea to a prostaglandin F2 $\alpha$ analogue, alfaprostol, during pseudopregnancy. Prostaglandins 56 255-264.

Boiti C, Zerani M, Zampini D \& Gobbetti A 2000 Nitric oxide synthase activity and progesterone release by isolated corpora lutea of rabbits in early- and mid-luteal phase of pseudopregnancy are differently modulated by prostaglandin E- 2 and prostaglandin F-2 $\alpha$ via adenylate cyclase and phospholipase C. Journal of Endocrinology 164 179-186.

Boiti C, Zampini D, Zerani M, Guelfi G \& Gobbetti A 2001 Prostaglandin receptors and role of $G$ protein-activated pathways on corpora lutea of pseudopregnant rabbit in vitro. Journal of Endocrinology 168 141-151.

Bonello N, McKie K, Jasper M, Andrew L, Ross N, Braybon E, Brannstrom M \& Norman RJ 1996 Inhibition of nitric oxide: effects on interleukin- $1{ }_{\alpha}$-enhanced ovulation rate, steroid hormone, and ovarian leukocyte distribution at ovulation in the rat. Biology of Reproduction 54 436-445.

Browning JY, Keyes PL \& Wolf RC 1980 Comparison of serum progesterone, $20 \alpha$-dihydroprogesterone, and estradiol-17 $\beta$ in pregnant and pseudopregnant rabbits: evidence for postimplantation recognition of pregnancy. Biology of Reproduction 23 1014-1019.

Chatterjee S, Gangula PR, Dong YL \& Yallampalli C 1996 Immunocytochemical localization of nitric oxide synthase-III in reproductive organs of female rats during the oestrous cycle. Histochemical Journal 28 715-723.

Coers W, Timens W, Kempinga C, Klok PA \& Moshage H 1998 Specificity of antibodies to nitric oxide synthase isofoms in human, guinea pig, rat and mouse tissues. Journal of Histochemistry and Cytochemistry 46 1385-1391.

Dharmarajan AM, Mastroyannis C, Yoshimura Y, Atlas SJ, Wallach EE \& Zirkin BR 1988 Quantitative light microscopic analysis of corpus luteum growth during pseudopregnancy in the rabbit. Biology of Reproduction 38 863-870.

Faletti A, Martinez SP, Perotti C \& de Gimeno MA 1999 Activity of ovarian nitric oxide synthase (NOS) during ovulatory process in the rat: relationship with prostaglandins (PGs) production. Nitric Oxide 3 340-347.

Förstermann U, Gath I, Schwarz P, Closs EI \& Kleinert H 1995 Isoforms of nitric oxide synthase. Properties, cellular distribution and expressional control. Biochemical Pharmacology 50 1321-1332.

Förstermann U, Boissel J-P \& Kleinert H 1998 Expressional control of the 'constitutive' isoforms of nitric oxide synthase (NOS I and NOS III). FASEB Journal 12 773-790.

Fridén BE, Runesson E, Hahlin M \& Brannstrom M 2000 Evidence for nitric oxide acting as a luteolytic factor in the human corpus luteum. Molecular Human Reproduction 6 397-403.

Gobbetti A, Zerani M \& Bellini-Cardellini L 1992 Relationships among mammalian gonadotropin-releasing hormone, prostaglandins and sex steroids in the brain of crested newt, Triturus carnifex. Prostaglandins 44 209-218.

Gobbetti A, Boiti C, Canali C \& Zerani M 1999 Nitric oxide synthase acutely regulates progesterone production by in vitro cultured rabbit corpora lutea. Journal of Endocrinology 160 275-283.

Hesla JS, Preutthipan S, Maguire MP, Chang TS, Wallach EE \& Dharmarajan AM 1997 Nitric oxide modulates human chorionic gonadotropin-induced ovulation in the rabbit. Fertility and Sterility $67548-552$.

Holt JA 1989 Regulation of progesterone production in the rabbit corpus luteum. Biology of Reproduction 40 201-208.

Hoyer PB, Keyes PL \& Niswender GD 1986 Size distribution and hormonal responsiveness of dispersed rabbit luteal cells during pseudopregnancy. Biology of Reproduction 34 905-910.

Jablonka-Shariff A \& Olson LM 1997 Hormonal regulation of nitric oxide synthases and their cell-specific expression during follicular development in the rat ovary. Endocrinology 138 460-468. 
Miller JB \& Keyes PL 1978 Transition of the rabbit corpus luteum to estrogen dependence during early luteal development. Endocrinology 102 31-38.

Moncada S, Palmer RMJ \& Higgs EA 1991 Nitric oxide: physiology, pathophysiology, and pharmacology. Pharmacological Reviews $\mathbf{4 2}$ 109-142.

Motta AB \& Gimeno MAF 1997 Nitric oxide participates in the corpus luteum regression in ovaries isolated from pseudopregnant rats. Canadian Journal of Physiology and Pharmacology 75 1335-1339.

Nakamura Y, Kashida S, Nakata M, Takiguchi S, Yamagata Y, Takayama H, Sugino N \& Kato H 1999 Changes in nitric oxide synthase activity in the ovary of gonadotropin treated rats: the role of nitric oxide during ovulation. Endocrine Journal 46 529-538.

Niswender GD, Juengel JL, Silva PJ, Rollyson MK \& McIntush EW 2000 Mechanisms controlling the function and life span of the corpus luteum. Physiological Reviews 80 1-29.

Olson LM, Jones-Burton CM \& Jablonka-Shariff A 1996 Nitric oxide decreases estradiol synthesis of rat luteinized ovarian cells: possible role for nitric oxide in functional luteal regression. Endocrinology 137 3531-3539.

Schmidt HHHW \& Walter U 1994 NO at work. Cell 78 919-925.

Shukovski L \& Tsafriri T 1995 The involvement of nitric oxide in the ovulatory process in the rat. Endocrinology 135 2287-2290.

Snyder SH \& Bredt DS 1992 Biological roles of nitric oxide. Scientific American 5 28-35.

Sokal RR \& Rohlf FJ 1981 Biometry, pp 253-261. New York: WH Freeman and Co.

Srivastava V, Jones BJ, Dookwah H, Hiney JK \& Dees WL 1997 Ovarian nitric oxide synthase (NOS) gene expression during peripubertal development. Life Sciences 61 1507-1516.
Van Voorhis BJ, Dunn MS, Snyder GD \& Weiner CP 1994 Nitric oxide: an autocrine regulator of human granulosa-luteal cell steroidogenesis. Endocrinology 135 1799-1806.

Van Voorhis BJ, Moore K, Strijbos PJ, Nelson S, Baylis SA, Grzybicki D \& Weiner CP 1995 Expression and localization of inducible and endothelial nitric oxide synthase in the rat ovary. Effects of gonadotropin stimulation in vivo. Journal of Clinical Investigation 96 2719-2726.

Vega M, Johnson MC, Diaz HA, Urrutia LR, Troncoso JL \& Devoto L 1998 Regulation of human luteal steroidogenesis in vitro by nitric oxide. Endocrine 8 185-191.

Watanabe Y, Nishio M, Hamaji S \& Hidaka H 1998 Inter-isoformal regulation of nitric oxide synthase through heteromeric dimerization. Biochimica et Biophysica Acta 1388 199-208.

Weiner CP, Lizasoain I, Baylis SA, Knowles RG, Charles IG \& Moncada S 1994 Induction of calcium-dependent nitric oxide synthesis by sex hormones. PNAS $\mathbf{9 1}$ 5212-5216.

Yamauchi J, Miyazaki T, Iwasaki S, Kishi I, Kuroshima M, Tei C \& Yoshimura Y 1997 Effects of nitric oxide on ovulation and ovarian steroidogenesis and prostaglandin production in the rabbit. Endocrinology 138 3630-3637.

Zackrisson U, Mikuni M, Wallin A, Delbro D, Hedin L \& Brannstrom M 1996 Cell-specific localization of nitric oxide synthases (NOS) in the rat ovary during follicular development, ovulation and luteal formation. Human Reproduction 11 2667-2673.

Received in final form 31 December 2001

Accepted 21 January 2002 